\title{
Pancreatic Enzymes in End-stage Renal Disease Patients on Maintenance Hemodialysis
}

\author{
Taoufiq Aatif ${ }^{1}$, Rachid Akka²
}

\begin{abstract}
Background: Elevated serum levels of pancreatic enzymes are frequently observed in end-stage renal disease (ESRD) in the absence of pancreatic diseases.

Aim: Evaluate the prevalence of elevated pancreatic enzymes in patients on maintenance hemodialysis (HD) and compare it with healthy controls. Materials and methods: Serum amylase (SA) and serum lipase (SL) levels were evaluated in 20 patients on maintenance HD (group I) and compared with levels in 25 healthy controls (group II).

Results: In group I, hyperamylasemia and/or hyperlipasemia were found in 14 (70\%) patients. Abnormal levels of both SA and SL simultaneously were noted in 7 (35\%); however, hyperamylasemia and hyperlipasemia only were noted, respectively, in $11(55 \%)$ and in 10 (50\%) patients. There was a significant moderate positive correlation between SA and serum creatinine (103.8 \pm 50.6 vs $89.9 \pm 20.9 ; r=0.48 ; p=0.029)$, and between SL and serum creatinine (61.2 40.1 vs $89.9 \pm 20.9 ; r=0.47 ; p=0.034)$ in group I. Mean SA values were significantly higher in group I in comparison with group II: $103.8 \pm 50.6$ vs $64.1 \pm 31.5 \mathrm{U} / \mathrm{L} ; p=0.005$, and mean SL values were significantly higher in group I in comparison with group II: $61.2 \pm 40.1$ vs $31.8 \pm 17.7 \mathrm{U} / \mathrm{L} ; p=0.002$.

Conclusion: Our results indicate that elevated serum levels of pancreatic enzymes in ESRD patients on maintenance HD is slight but frequently occurs. There is a general agreement that reduced glomerular filtration rate would be the cause. The occurrence of hypothetical concomitant pancreatic damage has been suggested and the complex hemodynamic, biochemical, and physiological alterations in uremia were speculated to cause an excessive release of pancreatic enzymes.

Keywords: Amylase, End-stage renal disease, Hemodialysis, Lipase, Pancreatic enzymes.

Indian Journal of Medical Biochemistry (2019): 10.5005/jp-journals-10054-0119
\end{abstract}

\section{INTRODUCTION}

Elevated serum levels of pancreatic enzymes are frequently observed in end-stage renal disease (ESRD) specially on maintenance hemodialysis (HD) in the absence of clinical pancreatitis. ${ }^{1-4}$ However, increased levels of serum amylase (SA) and serum lipase (SL) are indicators of acute pancreatitis, but these two enzymes are elevated in many non-pancreatic conditions also. Renal insufficiency is one of the common causes for such non-specific elevation. ${ }^{3}$ The mechanism of this elevation is not clearly understood. It is known that $24 \%$ of circulating amylase is excreted in urine. ${ }^{5}$ The lipase is filtered by glomeruli and almost completely reabsorbed and metabolized by the renal tubules. ${ }^{6}$ Therefore, the increase in serum levels of pancreatic enzymes reflects a reduce of glomerular filtration and is not generally due to pancreatic damage. ${ }^{7}$ The frequency of pancreatitis is higher in patients with renal impairment than in the general population, and the nonspecific increase in pancreatic enzymes makes diagnosis difficult for this complication. ${ }^{8}$ Laboratory confirmation of the diagnosis of pancreatitis is difficult in patients with ESRD, and cannot be supported only by SA and SL measurements. ${ }^{9}$ In the present study, we measured total SA and $S L$ activities in two groups of patients. The aim was to evaluate the prevalence of elevated pancreatic enzymes in patients on maintenance $\mathrm{HD}$ and compare it with healthy controls.

\section{Materials and Methods}

\section{Study Design}

We performed a monocentric cross-sectional comparative observational study, in Nephrology-Hemodialysis Department, at the 5th Military Hospital, Guelmim-Morocco. From June 2016

\footnotetext{
${ }^{1}$ Department of Nephrology-Hemodialysis, 5th Military Hospital, Guelmim, Morocco

2Department of Gastroenterology, 5th Military Hospital, Guelmim, Morocco

Corresponding Author: Taoufiq Aatif, Department of NephrologyHemodialysis, 5th Military Hospital, Guelmim, Morocco, Phone: +212 (0)528 7726 65, e-mail: taoufiq.aatif@usmba.ac.ma

How to cite this article: Aatif T, Akka R. Pancreatic Enzymes in Endstage Renal Disease Patients on Maintenance Hemodialysis. Indian J Med Biochem 2019;23(3):343-346.

Source of support: Nil

Conflict of interest: None
}

to December 2016, the Institutional Review Board approved this study protocol, and informed consent was obtained from all the patients.

\section{Patients Selection}

The study involved 45 subjects who were divided into two groups:

\section{Group I}

This group comprised 20 patients on ESRD on maintenance HD for at least 3 months and given conventional HD treatment, and were totally dependent on dialysis and were considered to have a complete loss of renal function.

\section{Group II}

This group contained 25 normal volunteers who served as controls (C).

(-) The Author(s). 2019 Open Access This article is distributed under the terms of the Creative Commons Attribution 4.0International License (https://creativecommons. org/licenses/by-nc/4.0/), which permits unrestricted use, distribution, and non-commercial reproduction in any medium, provided you give appropriate credit to the original author(s) and the source, provide a link to the Creative Commons license, and indicate if changes were made. The Creative Commons Public Domain Dedication waiver (http://creativecommons.org/publicdomain/zero/1.0/) applies to the data made available in this article, unless otherwise stated. 
None of the subjects presented clinical signs and symptoms of acute and chronic pancreatitis either during or before the study period. Alcohol intake was absent in the included patients. They were screened for infection, shock, salivary gland disease, cancer, and other known causes of hyperamylasemia and hyperlipasemia.

For HD patients, dialysis treatment consisted of three sessions weekly, and duration of four hours for each session. HD was performed using polyamide high-flux biocompatible synthetic membranes and bicarbonate-based dialysate. Ultrapure water was used. Regular microbiological tests showed no bacterial growth and endotoxin count was below $0.05 \mathrm{U} / \mathrm{mL}$. Dialysate flow rate: $500 \mathrm{~mL} / \mathrm{min}$; blood flow ranged from 320 to $350 \mathrm{~mL} / \mathrm{min}$. Automatic dialysis machines were employed (Gambro ${ }^{\oplus}$ AK 200 ultra S hemodialysis machine, Sweden).

\section{Evaluation Methods}

Demographic information and clinical history of patients were retrieved from medical records. For HD patients (group I), results of biochemical and hematological blood analyses performed in the same month under study were collected. In all subjects, blood samples were drawn after an overnight fast. In HD patients (group I), blood samples were obtained in the beginning of HD, via dialysis tubing.

SA and SL activities were measured using an enzymatic colorimetric assay (Roche/Hitachi Cobas c system). The normal ranges at our laboratory were, for SA: 28-100 U/L and for SL: 13-60 U/L. Serum creatinine was assayed using the Jaffe colorimetric method (normal ranges $7-12 \mathrm{mg} / \mathrm{L}$ ).

\section{Statistical Analysis}

Continuous variables are presented as mean values and standard deviation or median and quartiles. For categorical variables, effectives and percentages are given. Variables were compared using Mann-Whitney test or Chi-square test. For correlations, Pearson's test was used. All analysis was performed with the SPSS software (version 21.0), and a $p$ value lower than $5 \%$ was considered statistically significant.

\section{Results}

\section{Group I}

This group had $20 \mathrm{HD}$ patients, 10 females and 10 males, whose mean age was $56.8 \pm 13.9$ years. Median duration of HD was 55 months. ESRD originated from diabetic nephropathy 10 (50\%), interstitial nephritis $3(15 \%)$, vascular disease $2(10 \%)$ and unknown 5 (25\%). For HD treatment, vascular access were arteriovenous fistula in 15 (75\%), polytetrafluoroethylene (PTFE) grafts in 2 (10\%) and tunnelized catheters in $3(15 \%)$ patients. All patients were using polyamide high-flux membranes of $2.1 \mathrm{~m}^{2}$ in $12(60 \%), 1.7 \mathrm{~m}^{2}$ in $6(30 \%)$, and $1.4 \mathrm{~m}^{2}$ in $2(10 \%)$ patients. The demographic, HD, hematological, and hemodynamic data for group I (HD patients) are presented in Table 1.

Hyperamylasemia and/or hyperlipasemia were found in 14 (70\%) patients. Abnormal levels of both SA and SL were noted simultaneously in 7 (35\%) patients; however, hyperamylasemia and hyperlipasemia only were noted, respectively, in 11 (55\%) and in $10(50 \%)$ patients. Five (25\%) patients had SA higher than 1.5 times the upper reference limit (URL), but none of the patients had SA higher than 2 times the URL. SL was higher than 1.5 times the URL in 4 (20\%) patients and $3(15 \%)$ had levels higher than 2 times of URL, but none of the patients had levels higher than 3 times of
Table 1: Characteristics of hemodialysis patients

\begin{tabular}{ll}
\hline Variables & Values \\
\hline Patients $(n)$ & 20 \\
Age (years) & $56.8 \pm 13.9$ \\
Gender, $n$ (\%) female & $10(50)$ \\
Duration of HD (months) & $55[23-104]^{*}$ \\
Primary cause of ESRD $n$ (\%) & \\
$\quad$ Diabetes & $10(50)$ \\
$\quad$ Interstitial nephritis & $3(15)$ \\
$\quad$ Vascular & $2(10)$ \\
$\quad$ Unknown & $5(25)$ \\
Dry weight $(\mathrm{kg})$ & $64.1 \pm 12.8$ \\
SBP (mm Hg) & $132.1 \pm 15.3$ \\
DBP (mm Hg) & $78.9 \pm 10.2$ \\
CRP (mg/L) & $5.4[2.9-7.1]^{*}$ \\
Hct $(\%)$ & $32.7 \pm 4.9$ \\
Hemoglobin (g/dL) & $10.58 \pm 1.7$ \\
Ferritin $(\mathrm{ng} / \mathrm{mL})$ & $414.9[221.3-510.3]^{*}$ \\
Albumin (g/L) & $33.7 \pm 3.3$ \\
PTHi (pg/mL) & $465.3[216.2-667.8]^{*}$ \\
Calcium (mg/L) & $81.6 \pm 7.2$ \\
Phosphorus (mg/L) & $34.4 \pm 11$ \\
Kt/V urea & $1.34 \pm 0.1$ \\
\hline Datare expressedas &
\end{tabular}

Data are expressed as number and percentage or mean \pm standard deviation; *Expressed as median [quartiles]

$H D$, hemodialysis; ESRD, end-stage renal disease; SBP, systolic blood pressure; DBP, diastolic blood pressure; CRP, C-reactive protein; $\mathrm{HCT}$, hematocrit; PTHi, intact parathyroid hormone

URL. The correlation coefficient of serum creatinine and pancreatic enzymes was calculated to evaluate the relationship between the renal function and the levels of pancreatic enzymes. There was a significantly moderate positive correlation between SA and serum creatinine $(103.8 \pm 50.6$ vs $89.9 \pm 20.9 ; r=0.48 ; p=0.029)$, and between SL and serum creatinine $(61.2 \pm 40.1$ vs $89.9 \pm 20.9$; $r=0.47 ; p=0.034$ ) (Figs 1 and 2).

\section{Group II}

This group consisted of 25 healthy controls, 15 females and 10 males, whose mean age was $52.2 \pm 13$ years.

There was no significant difference between group I and group II for age and gender. Mean SA values were significantly higher in group I in comparison with group Il: $103.8 \pm 50.6$ vs $64.1 \pm 31.5 \mathrm{U} / \mathrm{L}$; $p=0.005$, and mean SL values were significantly higher in group I in comparison with group II: $61.2 \pm 40.1$ vs $31.8 \pm 17.7 \mathrm{U} / \mathrm{L} ; p=0.002$ (Table 2, Figs 3 and 4).

\section{Discussion}

Our study demonstrated that means SA and SL were significantly higher in group I (HD patients) in comparison with group II (healthy controls). Elevated serum levels of pancreatic enzymes had reported in patients with renal dysfunction, ${ }^{1,3,4}$ but the underlying mechanism is still unclear. Although there is general agreement that a reduced glomerular filtration rate can result in a slight enhancement of pancreatic enzymes in a great number of patients with chronic renal disease, the presence of very high levels in a minority of cases is still a matter of debate. 


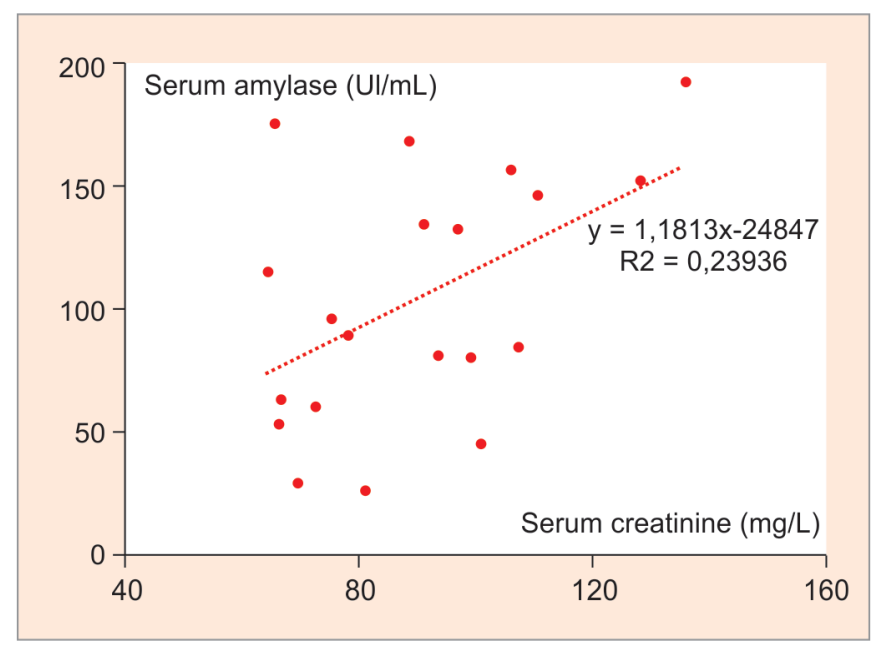

Fig. 1: Relation between serum creatinine and serum amylase in group I (hemodialysis patients) $(r=0.48 ; p=0.029)$

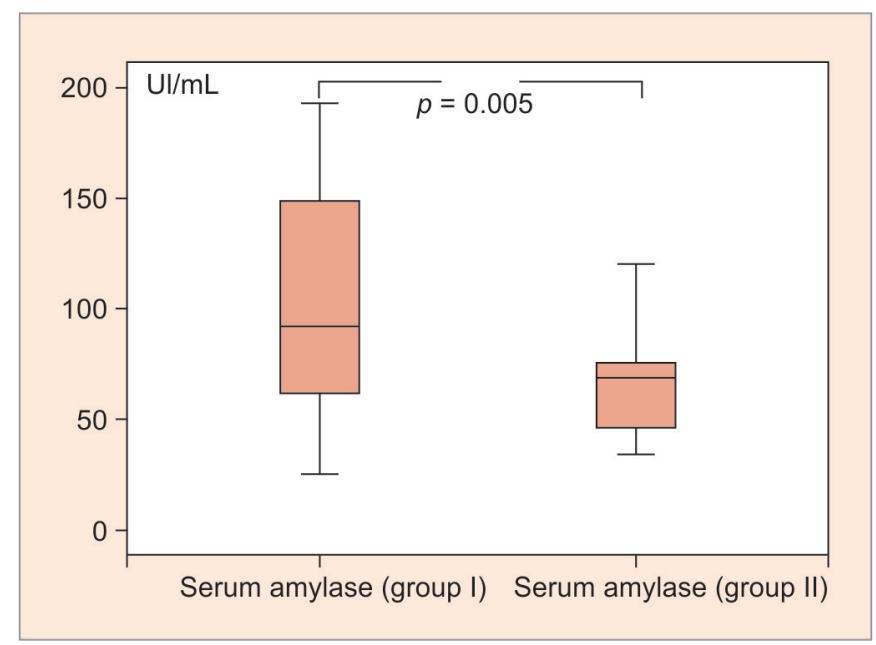

Fig. 3: Distribution of levels of serum amylase in study groups

Table 2: Characteristics and comparison of hemodialysis patients and the healthy controls

\begin{tabular}{llll}
\hline & $\begin{array}{l}\text { Group l: hemo- } \\
\text { dialysis patients } \\
(n=20)\end{array}$ & $\begin{array}{l}\text { Group II: } \\
\text { healthy controls } \\
(n=25)\end{array}$ & $p$ \\
\hline Age (years) & $56.8 \pm 13.9$ & $52.2 \pm 13$ & 0.123 \\
Gender (M/F) & $10 / 10$ & $10 / 15$ & 0.502 \\
Serum amylase (U/L) & $103.8 \pm 50.6$ & $64.1 \pm 31.5$ & 0.005 \\
Serum lipase (U/L) & $61.2 \pm 40.1$ & $31.8 \pm 17.7$ & 0.002 \\
Serum creatinine & $89.9 \pm 20.9$ & $6.4 \pm 1.4$ & $<0.0001$ \\
(mg/dL) & & & \\
\hline
\end{tabular}

On the basis of the findings, in postmortem studies of a variety of pancreatic abnormalities in patients with ESRD, ${ }^{1}$ the occurrence of hypothetical concomitant pancreatic damage has been suggested. The complex hemodynamic, biochemical, and physiological alterations in uremia were speculated to cause an excessive release of pancreatic enzymes. ${ }^{1}$ Many studies have addressed the influence of biochemical factors such as serum creatinine, urea nitrogen, triglycerides, or parathyroid hormone (PTH). ${ }^{1-4,10,11}$ However,

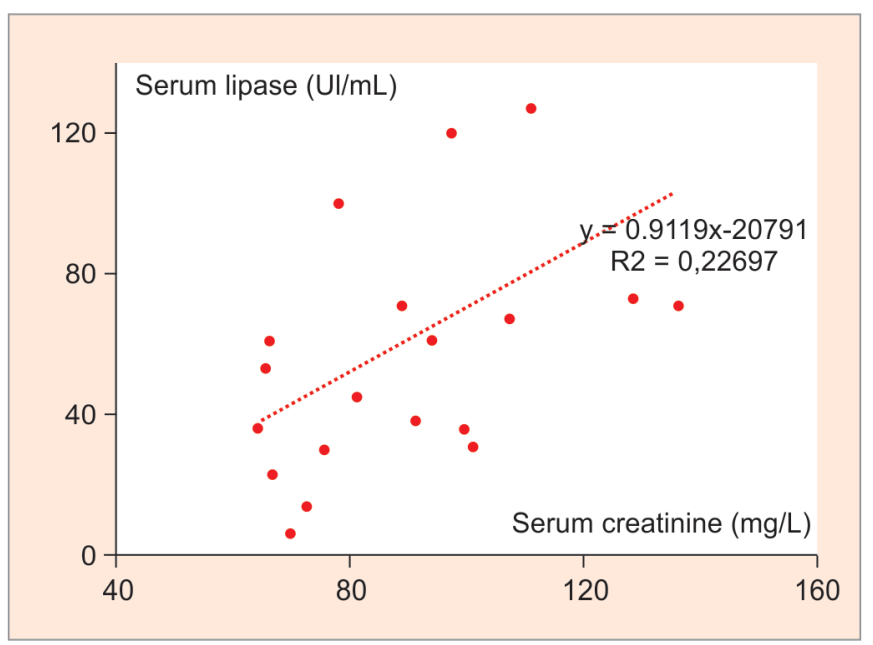

Fig. 2: Relation between serum creatinine and serum lipase in group I (hemodialysis patients) $(r=0.47 ; p=0.034)$

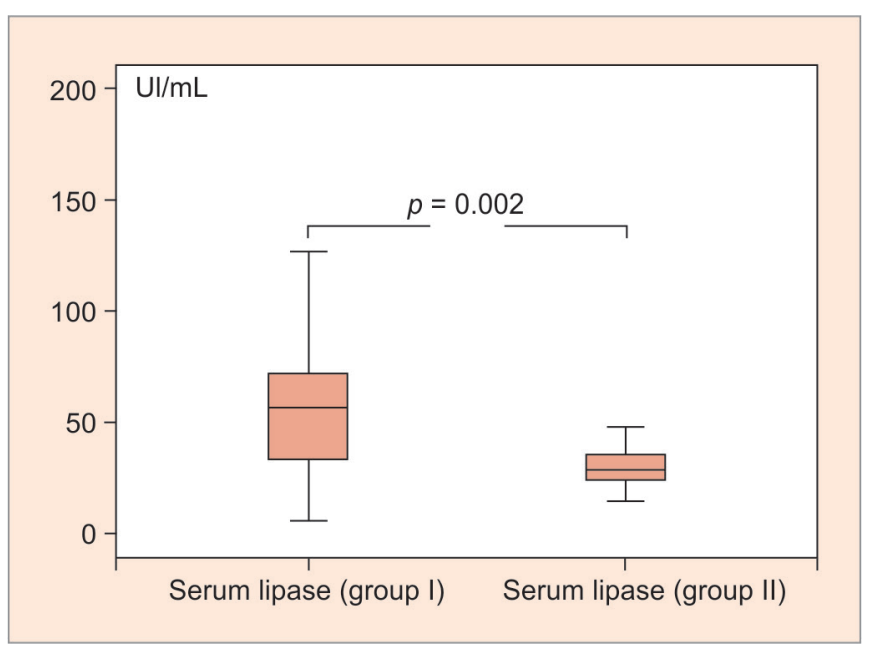

Fig. 4: Distribution of levels of serum lipase in study groups

Chen et al. proved that hemodynamic changes during HD and related factors are significantly associated with elevated SA. ${ }^{12}$

Berk et al. ${ }^{13}$ indicated that hyperamylasemia was found in $50 \%$ of their uremic patients, and fewer than three times the URL. Hyperlipasemia was reported by Sommer et al. ${ }^{14}$ in $46 \%$ and by Zachee et al. ${ }^{15}$ in $65 \%$ of their patients. Jiang et al. ${ }^{2}$ in their study on patients with ESRD found high levels of SA and SL in $60.7 \%$ and $57.1 \%$, respectively. Elevated levels of serum pancreatic enzymes up to three times the URL was reported in $60-80 \%$ of the patients under maintenance HD who do not have evidence of acute pancreatitis. ${ }^{1-4}$

In our study, hyperamylasemia and/or hyperlipasemia were found in $70 \%$. Abnormal levels of both SA and SL simultaneously were noted in 35\%; however, hyperamylasemia and hyperlipasemia only were noted, respectively, in $55 \%$ and in $50 \%$ of patients. $25 \%$ patients had SA higher than 1.5 times the URL, but none of the patients had SA higher than 2 times the URL. SL was higher than 1.5 times the URL in 4 (20\%) patients and $3(15 \%)$ had levels higher than 2 times of URL, but none of the patients had levels higher than 3 times of URL. An SA value more than 10 times the URL may indicate pancreatic injury in patients with renal insufficiency but SL has no diagnostic value. ${ }^{3,15}$ Similar to our findings, Lin et al. ${ }^{3}$ and 
Gross et al. ${ }^{16}$ found that there was a positive correlation between SA and serum creatinine, and between SL and serum creatinine.

Patients with ESRD commonly have nausea, vomiting, and abdominal discomfort, which are also seen in pancreatitis. Owing to the significantly elevated levels of pancreatic enzymes in uremia, the differential diagnosis becomes difficult. ${ }^{8}$

\section{CONCLUSION}

There is an evidence that interpretation of elevated serum levels of pancreatic enzymes in ESRD patients on HD needs an awareness of the non-specific increase seen in this population. In difficult cases, it may be necessary to follow serial enzyme levels and interpret them in the context of the clinical course and the results of imaging and other appropriate investigations.

\section{Meeting Presentation}

Partial data on this manuscript has been presented as a poster communication at the 2nd SFNDT congress (Nice, France, 9-13 October 2017).

\section{References}

1. Masoero G, Bruno M, Gallo L, et al. Increased serum pancreatic enzymes in uremia: Relation with treatment modality and pancreatic involvement. Pancreas 1996;13:350-355. DOI: 10.1097/00006676199611000-00004.

2. Jiang CF, Ng KW, Tan SW, et al. Serum level of amylase and lipase in various stages of chronic renal insufficiency. Zhonghua Yi Xue Za Zhi (Taipei) 2002;65:49-54.

3. Lin XZ, Chen TW, Wang SS, et al. Pancreatic enzymes in uremic patients with or without dialysis. Clin Biochem 1988 Jun;21:189-192. DOI: 10.1016/0009-9120(88)90009-4.
4. Vaziri ND, Chang D, Malekpour A, et al. Pancreatic enzymes in patients with end-stage renal disease maintained on hemodialysis. Am J Gastroenterol 1988;83(4):410-412.

5. Bailey GL, Katz Al, Hampers CL, et al. Alterations in serum enzymes in chronic renal failure. JAMA 1970;213:2263-2265. DOI: 10.1001/ jama.1970.03170390053014.

6. Salt W, Schenker S. Amylase-its clinical significance, a review of literature. Medicine (Baltimore) 1976 Jul;55(4):269-289. DOI: 10.1097/00005792-197607000-00001.

7. Tietz NW, Shuey DF. Lipase in serum - the Elusive enzyme, an overview. Clin Chem 1993;39(5):746-756.

8. Usha Rani S, Rama Rao J, Ambica Devi K. Effect of renal insufficiency on pancreatic enzyme activities in serum. J Sci 2015;5(4):232-234.

9. Thierry FX, Dueymes JM, Vernier I, et al. Serum lipase and amylase levels in chronic renal failure: interpretation of results-effects of extrarenal purification. Nephrologie 1988;9(6):263-267.

10. Koizumi M, Takada T, Kawarada Y, et al. JPN Guidelines for the management of acute pancreatitis: Diagnosis criteria for acute pancreatitis. J Hepatobiliary Pancreat Surg 2006;13:25-32. DOI: 10.1007/s00534-005-1048-2.

11. Bastani B, Mifflin TE, Lovell MA, et al. Serum amylases in chronic and end-stage renal failure: Effects of mode of therapy, race, diabetes and peritonitis. Am J Nephrol 1987;7:292-299. DOI: 10.1159/000167488.

12. Chen $\mathrm{Y}-\mathrm{H}$, Yang W-C, Wang F-M, et al. Risk factors associated with elevated serum pancreatic amylase levels during hemodialysis. Hemodial Int 2011;15:79-86. DOI: 10.1111/j.1542-4758.2010.00519.x.

13. Berk JE, Fridhandler L, Ness RL. Amylase and iso-amylase activities in renal insufficiency. Ann Intern Med 1979;90:351-353. DOI: 10.7326/0003-4819-90-3-351.

14. Sommer $H$, Kasper H, Fosel T. Serum lipase activity in chronic renal failure. Acta Hepatogastroenterol (Stuttg) 1975;22:248-252.

15. Zachee $P$, Lins RL, De Broe ME. Serum amylase and lipase values in acute renal failure. Clin Chem 1985;31:1237.

16. Gross JB, Parkin JW, Maher RT, et al. Serum amylase and lipase values in renal insufficiency. Ann Intern Med 1979;90:351-353. DOI: 10.7326/0003-4819-90-3-351. 